Volume: 11 Issue: 2 Year: 2014

\title{
Functionalist perspective on deviance
}

\author{
Sebahattin Ziyanak ${ }^{1}$ \\ James L. Williams ${ }^{2}$
}

\begin{abstract}
This paper focuses on and summarizes the functionalist perspective of deviance, the function of crimes, and how these perspectives have influenced the development of Durkheim's work, anomie, for example. In this regard, our aim is to carefully describe the contributions of important functionalist thinkers such as Emile Durkheim and Robert K. Merton, by providing a brief historical discussion that highlights their contributions to deviance and crime research. Further, we are also primarily interested in how the functionalist tradition has influenced contemporary works. In this regard, this paper focuses on the most relevant theories that are related to sources of strain including Robert Merton's "structural strain theory," Steven Messner and Richard Rosenfeld's "institutional anomie" and Richard Cloward and Lloyd Ohlin's "differential opportunity theory. This paper presents these contemporary thinker's views and in addition to that it presents a detailed discussion of their major studies published since 2000.
\end{abstract}

Keywords: Functionalist perspective; deviance; Durkheim; Merton; anomie; institutional anomie; micro anomie; differential opportunity

\section{Functionalist Perspective}

The structural perspective was the dominant understanding in the sociology literature of the first half of the twentieth century. Durkheim, whose writings have played a central role in the understanding of deviance, argued that crime and deviance are not created by a small number of sick individuals, nor are these situations unnatural in any way, rather they are an essential part of society. In turn, crime performs an absolutely crucial function. Durkheim's main argument was based on the functionality of deviance in any society. Durkheim (1951) confirmed the obvious negative effects of deviance. Besides negative influences of deviant behavior, he also identified that deviance yields positive benefits for society.

\footnotetext{
${ }_{1}^{1}$ Ph.D., Instructional Associate/Coach Academic Partnerships, sebahattin.ziyanak@iconnect-na.com

2 Professor; Sociology Department Chair; Criminal Justice Program Director, Texas Woman University, JWilliams2@,twu.edu
} 
In that way alone, unlike other functionalist perspective on deviance, Emile Durkheim, and Robert K. Merton held common basic ideas concerning acts of deviance. They avowed that such actions could be seen in a positive way, because they could be used to point out the ideas of right and wrong in society. Moreover, society itself had to be considered to recognize the functionalist analysis of deviance. Hence, a functionalist analysis of deviance and crime begins with society as a whole, rather than by observing or merely focusing on the motives and purposes of individuals.

\section{Historical Background}

\section{Durkheim's Perspective on Deviance}

Durkheim (1951) indicated that after all, crime plays a constructive role in society through its bond forging influence among the non-criminal population; for example, this may occur when a crime strengthens the collective conscience through the creation of boundaries for human conduct such as the approving of deviants. Durkheim (1951) alleged that crime is a normal functioning force behind the social order, moral parameters, and that crime is therefore, important and inevitable in every society.

Edward Ross argued that social institutions foster social control. Similar to Durkheim, Ross placed emphasis on social institutions such as religion, public opinion, and specifically education (as cited in Deflem, 2007). Ross perceived that these social institutions applied to everyone in society, not just to the criminal who violates normative expectations (as cited in Deflem, 2007). The study of social control in Ross's analysis is developed against the background of awareness for social problems such as urbanization, poverty, alcoholism, and prostitution (as cited in Deflem, 2007).

Durkheim (1984) acknowledged that the division of labor had economic benefits. But it had another function, beyond increasing economic success, production of goods, and affluence. Further, elaboration of the notion of multiple functionalism is noted in the publication entitled "The Division of Labor" where Durkheim underlines that, punishment does not only serve to "correct the guilty person or to scare off any possible imitators" (Durkheim, 1984, p. 62); but it also functions to "maintain inviolate the cohesion of society" (p.62).

In his classic work called "Suicide", Durkheim (1951) affirmed that "society is not only something fascinating the sentiments and actions of persons with uneven force but it is also a power operating them" (Durkheim, 1951, p. 241). Durkheim (1951) illustrated the presence of social anomie and social relationship in an insightful way with his classification of anomic suicide to comfort French society. From this point of view, Durkheim delineated anomic suicide as the product of "man's activities lacking regulation and consequent sufferings" (p. 258). Touching on this social order, 

9. doi: $\underline{10.14687 / \text { ijhs.v11i1.2791 }}$

Durkheim explicated suicide cases on the origin of macro-level grounds such as moral degradation and social deregulation in society (Durkheim, 1951, p. 254). According to Durkheim, (1951) as a result of divorce, death of a spouse and being single (p. 259) another form of anomie called domestic anomie happens. As a consequence of this focus, Durkheim views marriage as an essential and permanent social foundation adjusting the sexual life of persons. More bluntly, marriage maintains communal stability between men and women in society (Durkheim, 1951). In relation to this indication, any adjustment in marital status may possibly yield distinct consequences for men and women as well as massive negative consequences for entire society (p. 266).

\section{Merton Perspective on Deviance}

Chiefly, Merton's notion of anomie was grounded on the "analysis of actions deviating from prearranged patterns of behavior" and the account of in what manner "frequency of deviant conduct differs within different social structures and by what means it chances that the deviances have different natures and forms in different social constructions” (Merton, 1968, p. 185).

Merton constantly underlined the point that "Emile Durkheim's study of the social functions of punishment centered upon its latent functions which implied consequences of community rather than confined to manifest functions which referred consequences for the criminal" (Merton, 1968, p. 115). Furthermore, Merton (1968) concluded that Durkheim indicated the foremost function of punishment as dynamism of cohesion.

In association to Durkheim's approach, Merton (1968) endeavored to find out the influence of social construction on the individual and in addition to that he distinguished his work by examining "the effect of cultural motivations and social means on the persons" (Coser, 1969, p. 504). In view of these developments, within the American functionalist tradition, Durkheim's concepts on social anomie facilitated Merton to form his own unique notions.

Merton (1938) first introduced this new theoretical approach regarding social anomie in "Social Structure and Anomie". Correspond to Durkheim's thoughts on anomie, Merton stressed that the dysfunction of the social structure is unquestionably leading in a sense that it may produce distinctive asocial performance by cause of "dissociation of culturally defined goals and socially structured means" (Merton, 1938, p. 674). In addition to that, Merton (1968) affirmed that these aforementioned classifications are not actually certain in a sense that "individuals may switch from one choice to another as they involve in different social activities" (Merton, 1968, p. 194). 


\section{Concluding Remarks on Anomie}

Durkheim and Merton considered social anomie in social context as a result of the existing social disorder rather than centering on characteristic behaviors. According to Durkheim (1951), anomie was a common occurrence. Likewise, Merton emphasized that "social structures apply a definite tension upon certain individuals in society to occupy in non-conforming rather than conforming behavior" (Merton, 1968, p. 186). The important point to grasp is that Merton (1968) views anomie as reasonably a normal social phenomenon.

\section{Contemporary View on Merton's Multilevel Theory}

Baumer (2007) asserted that Merton presented a multilevel theory that held that "emergent properties of communities shape the value commitments of individuals, which in turn lead to individual differences in deviant behavior" (Baumer, 2007, p. 66). Baumer (2007) comprised cultural program or education, as well as numerous individual factors, in addition to the factors that impact the process of anomie.

Baumer (2007) clarified the fact that the probability of innovative behavioral reactions among individuals who has a relatively weak commitment to normative means for pursuing those aforementioned goals will be greater. Further, individuals who are strongly committed to pursuing financial success goals will be strongly committed to legitimate means and conformity in social systems is the possible result.

In sum, Baumer (2007) stated that criminality will be more likely to arise in " those individuals who also feel mostly apart from appropriate chances through which monetary rewards might be achieved, those who lack major promises to other culturally esteemed success goals, those who distinguish the risk of punishment to be least, those who are displeased with their current financial conditions and those whose deviance conducive value commitments are reinforced by sustained exposure to others who have similar principles" (p. 77).

\section{Robert Agnew's General Strain Theory}

Agnew (2002) addressed the similarities between the macro level theory of anomie and control theory, but asserted that the micro level theory of strain should be considered separate from control theory. According to Agnew (2002), strain theory is based on the pressure that is placed on the individual to commit crimes (p.49). For Agnew, social learning theory focused on the forces from the group that led to a positive view of crime (p.49). He (2002) stated that the status of strain/anomie theory declined in the late 1960's due to the lack of empirical evidence. In general, Agnew (2002) addressed many of the criticisms of the original strain theory. 


\section{Institutional Anomie Theory}

Messner and Rosenfeld's institutional anomie theory suggested that an inescapable cultural order to attain money, attached with an anomic normative setting that takes place from an evident disparity of power in favor of the economy over all other social establishments impacts this course. In this sense, both scholars (1994) claimed that this set of circumstances was responsible for the high rates of serious crimes found in the United States. This argument was discussed by many other scholars in the analysis of structural functionalism.

In institutional anomie theory, Messner and Rosenfeld (1994) also focused on high crime rates in the United States. They described the American Dream as the "broad cultural ethos that entails a commitment to the goal of material success, to be pursued by everyone in society, under conditions of open, individual competition.” (Messner \& Rosenfeld, 1994. p. 3). For them, this idea can be better understood in terms of four values achievement, individualism, and universalism.

Messner and Rosenfeld (1994) built their institutional anomie theory on the basis of the ideas proposed by Merton. Both scholars (1994) articulated the view that both less and more opportunity can lead to criminality. Yet, frustration related to not being able to legally meet one's goals due to the presence of less opportunity is commonly called "strain" (Messner \& Rosenfeld, 1994. p. 9). Institutional anomie theory adds that "an expansion of economic opportunities, rather than lessening the level of anomie in society, may actually intensify culturally induced pressures to use extralegal means to acquire monetary rewards.” (p. 10).

In regards to innovation and anomie and dominant societal institutions, Messner and Rosenfeld (2003) pointed out that the American Dream, especially its cultural and structural aspects comprise part of the problem.

Messner and Rosenfeld (2003) identified significant institutions in American society and claimed that the economy is the most important of the group. The institutions they noted included the economy, polity, family, and education, and they referred to the economy means as those "activities organized around the production and distribution of goods and services" (Messner \& Rosenfeld, 2003, p. 98). Their idea of polity referred to the political system which "mobilizes and distributes power to attain collective goals" (Messner \& Rosenfeld, 2003, p. 98). They argued that the family educates and interacts children "into the values, goals, and beliefs of the prevailing culture." (Messner \& Rosenfeld, 2003, p. 99). Lastly, education is accountable for "preparing youth for the demands of adult roles and, in particular, occupational roles.” (Messner \& Rosenfeld, 2003, p. 99). 


\section{Other Contemporary Thinkers' Views on Institutional Anomie Theory}

Bernburg (2002) argued that the various anomie perspectives that exist did not form a unified body of theory. For Bernburg, Durkheim's notion of anomie had changed fundamentally in the hands of American sociologists, and he stated that "American anomie theorists had not emphasized anomie in relation to the widespread lack of socially valued goals" (Bernburg, 2002, p. 701). In his informed research, he sought to investigate questions, such as "have any of the recent developments in American anomie theory moved beyond the consolation of liberal society; have they shifted from focusing from Mertonian normlessness of means and to Durkheimian normlessness of ends" (Bernburg, 2002, p. 730).

Bernburg (2002) identified institutional anomie theory as a macro level theory that aimed to focus on societal level processes. He (2002) mentioned how institutional anomie theory differs from proper anomie theories of crime and deviance. In reference to that idea, he also (2002) elaborated on how the institutional anomie theory had departed from Merton's notion of anomie.

According to Bernburg (2002), the American Dream thus "creates pressure to achieve, but minimizes the pressure to play by the rules" (p. 732). To Bernburg, "under these circumstances, people are more likely to use the "most technically efficient means necessary" in reaching their goals (p. 733). Bernburg (2002) observed that the outcome of all this was a greater rate of aggressive crime.

Chamlin and Cochran (2007) confirmed that when noneconomic institutions such as the family, schools, and polity are strong, the effects of economic pressure on both property crimes and violent crimes are weaker.

Furthermore, Chamlin and Cochran (2007) studies took a different direction from that of Messner and Rosenfeld's institutional anomie theory. Chamlin and Cochran (2007) tested the theory's underlying assumptions, and according to their results, the applicability of institutional anomie theory may be limited to western nation-states (Chamlin \& Cocohran, 2007). In conclusion, Chamlin and Cochran's research supported this theoretical perspective and proposed that the American Dream is criminogenic.

\section{Concluding Remarks}

Institutional anomie theory stipulates a reciprocal causal relationship between the prevailing culture and institutional structures (Bernburg, 2002, p. 732). As described, most importantly it stresses the dominance of the market economy. In this sense, the cultural ethos is characterized by American Dream (Bernburg, 2002). 
Taken as a whole, contemporary scholars outline the institutional anomie theory and also argue about the problems associated with this approach (Chamlin \& Cochran, 2007; Jensen, 2002). According to Jensen (2002), one problem is firstly that institutional anomie theory is not directly testable; instead it has been assessed indirectly by examining the impact of various economic variables on crime rates. Some research in this area calls into question the assumption of institutional anomie theory, which implies that Americans value money above other institutions such as the family (Jensen, 2002).

Chamlin and Cochran (2007) concluded their study by comparing a larger and more heterogeneous (with respect to economic development) sample of countries. Yet, Messner and Rosenfeld's main assumption regarding American culture were not supported (Chamlin \& Cochran, 2007).

\section{Micro Anomie}

Similar to Merton, Konty (2005) articulated the idea of strain in reference to institutionalized means. He agrees with Melton's view. In a supportive manner to Merton, Konty (2005) stated that achieving success put vigorous pressure on individual and an individual exerts enormous efforts to get rid of this pressure to succeed (Konty, 2005. p. 107). One possible accommodation to strain is rejection of the institutionalized means of achievement and the replacement of this with deviant or illegitimate means to achieve the proscribed goals (Innovation). Further, other individuals might basically remain playing the game (Ritualism), relinquish and withdraw (Retreatism), or generate new easier goals to achieve and live with (Rebellion).

According to Merton (1968) anomie appears at the individual level. For him, micro anomie refers to a cognitive state and this happens when an individual is not regulated by morals, means, and norms (Merton, 1968). When an individual's value orientation is skewed toward self, he/she is unregulated by social interests. Hence, he/she is prone to operate against them. In turn, this situation is more likely to create criminal activities.

\section{Differential Opportunity}

Cloward and Ohlin (1961) and their ideas correspond with Merton's central thesis concerning strain. They (1961) discussed how man's desires for wealth are virtually unlimited. They (1961) stated that despite the dominant system of equal opportunity, every individual who has differently positioned in the social order obtains dissimilar chances of getting common achievement and in following of the American Dream constructs spirits of strain in individuals, or what Cloward and Ohlin (1961) termed "a major problem of adjustment" (p. 1). 
Cloward and Ohlin (1961) used Robert Merton's basic ideas concerning shared values and norms to individual subcultures in the smaller groups within cultures, or cultures within cultures. According to Cloward and Ohlin (1961) conflict among that share values and norms with those of the larger culture are different from each entity. In this regard, strain can lead to shared feelings of oppression among individuals as well as criminality. The inequality among lower-class youth mandates them to pursue "available source of a major problem of adjustment" (Cloward \& Ohlin, 1961, p. 108). This may apply to adolescents who form delinquent subcultures (Cloward \& Ohlin, 1961).

In a study of adolescent male delinquent gangs in large, lower-class, urban areas, by Cloward and Ohlin (1961), three types of prevailing subcultures were discovered. First, the criminal subculture, which was "a type of gang group that is devoted to larceny, extortion, and other illegal criminal behaviors" (Cloward \& Ohlin, 1961, p. 145). Second, the conflict subculture, which was "a type of gang group that controls the violence and prevails as a way of winning status" (p. 145). Third, the retreatist subculture which was "a type of gang group use drugs and alcohol” (p. 145).

Cloward and Ohlin (1961) explained that "If, in a given social location, illegal or criminal means are not readily available, then we should not expect a criminal subculture to develop among adolescents. According to the same logic, we should expect the manipulation of violence to become a primary avenue to achieving higher status only in those areas where the means of violence are not denied to the young (Cloward \& Ohlin, 1961, p. 85).

\section{Conclusion}

Surprisingly, more recent and many of the mentioned and elaborated empirical research studies have examined the additive and multiplicative effects of the structural antecedents of the institutional imbalance of power and anomie on violent and deviance and property crime rates. In this regard, all anomie and strain theories, to one degree or another show that crime is responsible for detrimental results and for strong influence of the economy on our lives.

\section{References}

Agnew, R. (2002). Experienced, vicarious, and anticipated strain: An exploratory study on physical victimization and delinquency. Justice Quarterly, 19: 603-632.

Bernburg, J. (2002). Anomie, social change and crime. The British Journal of Criminology, 42: 729-742.

Baumer, E. (2007). Untangling research puzzles in Merton's multilevel theory. Theoretical Criminology, $11(1): 66,73,77$. 
Chamlin, M. and Cochran, J. (2007). An evaluation of the assumptions that underlie institutional anomie theory. Theoretical Criminology, 11(1), pp. 41,51-53.

Cloward, R. and Ohlin, L. (1961). Delinquency and opportunity: A Theory of Delinquent Gangs. New York: The Free Press.

Coser, L. A. (1975). The idea of social structure papers in honor of Robert K. Merton. New York: Harcourt Brace Jovanovich.

Deflem, M. (2007). The concept of social control: Theories and applications. Presented at International Conference in Rennes, France. Retrieved 25 January, 2014 from http://deflem.blogspot.com/2007/08/concept-of-social-control-theories-and.html

Durkheim, E. (1951). Suicide: A study in sociology. Glencoe: IL. The Free Press.

Durkheim, E. (1984). The Division of labor in society. New York: N. Y. The Free Press.

Jensen, G. (2002). Institutional anomie theory and social variations in crime: A critical appraisal. International Journal of Sociology and Social Policy 22(7/8), pp. 58-60.

Konty, M. (2005). Micro anomie: The cognitive foundations of the relationship between anomie and deviance. Criminology, 43: 107-131.

Merton, Robert K. (1938). Social structure and anomie, American Sociological Review, 3(5), pp. 672682.

Merton, R. (1968). The Social theory of social structure. New York: N. Y. The Free Press.

Messner, S., and Rosenfeld, R. (1994). Crime and the American dream. New York.: Wadsworth.

Messner, S. (2003). An institutional-anomie theory of crime: Continuities and elaborations in the study of social structure and anomie, Cologne Journal of Sociology and Social Psychology, 43(1), pp. 98-9. 